specialties can reconcile their differences about the STI component. This could be a major problem; until both specialties work together to produce a combined specialty training scheme that will accept trainees with a background in either general medicine or gynaecology, the old divisions between the specialties will remain to the detriment of patient care.

\section{Career pathways}

Whether or not one agrees with the government direction and emphasis on teenage pregnancy and STIs this remains DH policy; there is a requirement for an integrated sexual health service including STI and contraceptive provision and community gynaecology. Currently there is no single career pathway in either medicine or nursing that addresses this need. The Faculty and GUM should reconsider the current proposed curriculum for the Certificate of Completion of Specialist Training (CCST) in SRH.

Many of the doctors staffing the clinics providing contraception are specialty and associate specialist (SAS) doctors because historically there has been no career structure. Some of the younger doctors have stopped applying for permanent posts because they believe that the new FSRH CCST will provide them with a career pathway to consultant level; but this may be unrealistic. The RCOG has an excess of doctors in training and hopes that some will be encouraged to work in the community on a parttime basis having achieved the competencies of the advanced training module in sexual health. ${ }^{2}$ In addition, the proposed new SRH specialist training will take entrants from obstetrics and gynaecology after they have completed 18 months training. There does not appear to be a pathway for the speciality SAS doctors to achieve consultant status except by Article 14. We need to be honest with our specialty doctors about their future career prospects and not encourage false expectations.

\section{Concluding remarks}

Service provision and career structure in SRH is changing. For many the integration with GUM services has resulted in a different pattern of clinical work from that for which they trained and wanted to practise. Change is inevitable and the service must evolve to give best care to patients. However, staff must be given adequate training and clinic integrations carefully planned if the new holistic sexual health service is to flourish.

\section{Statements on funding and competing interests Funding None identified.}

Competing interests None identified.

References

1 Department of Health. Better Prevention, Better Services, Better Sexual Health. The National Strategy for Sexual Health and HIV. London, UK: Department of Health, 2001. http://www.dh.gov.uk/en/Publicationsandstatistics/Publications/ PublicationsPolicyAndGuidance/DH_4003133 [Accessed 14 July 2009].

2 Royal College of Obstetricians and Gynaecologists (RCOG). The Future Workforce in Obstetrics and Gynaecology, England and Wales. Full Report. London, UK: RCOG Press, 2009. http://www.rcog.org.uk/news/future-workforce-obstetrics-andgynaecology [Accessed 14 July 2009].

\title{
The move to integrated contraception and sexual health services: have we forgotten family 'planning'?
}

\author{
Jill Shawe, Susan Mann, Judith Stephenson
}

\section{Background}

Recent reorganisation within primary care has seen community 'family planning' services become 'contraception and sexual health' (CASH) services, many integrating with genitourinary medicine clinics. With this we have seen a decrease in general community contraception clinics with women being asked to access general practitioner (GP) services for their basic contraceptive needs, and a corresponding increase in the development of clinics providing targeted services for specialised contraception and for young people in community settings.

J Fam Plann Reprod Health Care 2009; 35(4): 250-251

Centre for Sexual Health \& HIV Research, Department of Infection \& Population Health, University College London, London, UK

Jill Shawe, PhD, RN, Research Nurse

Judith Stephenson, MD, FFPHM, Margaret Pyke Professor of Sexual Reproductive Health

Margaret Pyke Centre, London, UK

Susan Mann, MFSRH, MFPHM, Research Associate

Correspondence to: Dr Jill Shawe, Centre for Sexual Health \& HIV Research, Department of Infection \& Population Health, 2nd Floor, Margaret Pyke Centre, 73 Charlotte Street, London W1T 4PL, UK. E-mail: jshawe@gum.ucl.ac.uk
Whilst this development has seen benefits in many ways, in contrast to the wide remit of 'family planning' clinics in reproductive health, it appears to have focused service delivery firmly on the prevention and treatment of sexually transmitted infections (STIs) and prevention of unintended pregnancies, in line with government guidelines and targets. ${ }^{1}$ It could be argued that although these are key objectives for CASH services, one crucial aspect of care that now appears to have less emphasis is promotion of pregnancy planning and preconception care.

\section{Importance of preconception care}

The importance of preconception care, including lifestyle and dietary review before conception, has been highlighted in the government's quest to reduce perinatal morbidity and mortality. ${ }^{2}$ Folic acid supplementation is recommended for all women planning pregnancy for 12 weeks prior to conception and for the first 12 weeks of pregnancy to prevent neural tube defects. ${ }^{3}$ Recent studies have affirmed additional benefits of folate supplementation in reducing both preterm birth ${ }^{4}$ and congenital heart defects. 5 Women who are planning pregnancy are advised to eat a healthy diet containing plenty of fresh fruit and vegetables, and in order to prevent teratogenicity and infection the Food Standards Agency has made some recommendations regarding preparation 
and consumption of specific foodstuffs including liver (high levels of vitamin A) and fish (high levels of mercury). Once pregnant, women should avoid unpasteurised cheeses (risk of listeria infection), undercooked poultry, eggs and cook-chill meals (risk of salmonella infection) and high caffeine intake (miscarriage risk and low birth weight). ${ }^{6}$

Other advice highlighted in reports from the British Medical Association ${ }^{7}$ and the Department of Health ${ }^{2}$ relate to the importance of not smoking and on alcohol consumption during pregnancy for all women, and to preconceptual screening for infections and genetic risk such as sickle cell and thalassaemia in high-risk women. In addition, there are concerns about environmental and occupational hazards such as heavy metals, organic solvents, pesticides and herbicides, anaesthetic gases and anti-cancer drugs used in health care. ${ }^{8}$

It appears that many women are not aware of these guidelines nor know how to access preconception care. ${ }^{2} \mathrm{~A}$ recent study ${ }^{9}$ found that few women planning a pregnancy complied with nutrition and lifestyle recommendations and concluded that greater effort and publicity is required to improve this situation. It seems that the practice of routinely asking women about plans for pregnancy and promoting preconception care during CASH consultations has declined significantly over the last 20 years. Possible explanations include time constraints, prioritisation of STI risk and discussion of long-acting reversible contraception (LARC); discontinuation of routine screening for rubella titre and genetic disease and the consequent reluctance to raise such issues when we are unable to provide such care. Instead women are directed to their GP, but it could be argued that women will only make time to visit their GP if they are already thinking about getting pregnant whereas opportunistic screening and preconception advice in CASH services may be a more effective strategy for reaching the target group.

Preconception care is particularly important for all women with medical conditions who should have their medication reviewed for potential teratogenicity [e.g. angiotensin-converting enzyme (ACE) inhibitors, which are increasingly used to control hypertension in younger women]. The current recommendation is that women with a risk of folate deficiency or with diabetes or epilepsy should be prescribed a higher dose $(5 \mathrm{mg})$ of folic acid as they are at higher risk of birth defects. Women with diabetes need to ensure good glycaemic control prior to conception to avoid poor maternal and fetal outcomes. Only $50 \%$ of women with diabetes plan their pregnancies and a recent population-based study 10 found a five-fold increased risk of stillbirth, a three-fold increased risk of perinatal mortality and a two-fold increased risk of fetal congenital anomaly for women with diabetes linked to poor glycaemic control.

\section{Demographic and epidemiological factors}

Demographic and epidemiological changes have led to a rise in conditions where preconception care could be of particular benefit: the rise in obesity that is linked to reduced fertility and subsequent potential for development of type 2 diabetes; the rise of STIs including chlamydia and HIV; and the fact that women are delaying childbearing with the implications of a possible decline in their fertility and increased pregnancy complications. Many women hold the false belief that the problem of the biological clock can be solved by assisted conception or in vitro fertilisation (IVF) if they have not conceived spontaneously in later life. The reality is quite different: live birth rates fall steeply in women over the age of 35 years - whether fertilisation happens in vivo or in vitro to only $5 \%$ or $10 \%$ per cycle of IVF in women aged over 40 years. ${ }^{11}$

Increasing evidence of the potential benefits of preconception care is shown by studies on the 'fetal origins of adult disease'. Accumulating evidence indicates that future health and susceptibility to disease are determined by processes occurring over an individual's lifespan. This 'life course approach' to disease highlights the importance of the intrauterine environment in preventing future disease and the preconception period is seen as a critical period where intervention can incur long-term benefit. ${ }^{12}$ Raising awareness of preconception care has therefore never been more important.

\section{Concluding remarks}

Proactive discussion of preconception care and pregnancy planning should be an integral part of all contraception and reproductive health services wherever they are provided. National Health Service CASH services and GP surgeries can provide the ideal setting in which to promote good health before pregnancy and offer a holistic preconception service. Future generations of children could be affected by the health and lifestyle of their mothers at conception; so as reproductive health practitioners, let us not forget family 'planning' and promote preconception care.

Statements on funding and competing interests

Funding None identified.

Competing interests None identified.

\section{References}

1 Department of Health. Choosing Health: Making Healthy Choices Easier (Cm 6374). 2004. http://www.dh.gov.uk/ en/Publicationsandstatistics/Publications/PublicationsPolicy AndGuidance/DH_4094550 [Accessed 12 June 2009].

2 Department of Health. National Service Framework for Children, Young People and Maternity Services: Maternity Services. 2007. http://www.dh.gov.uk/en/Publicationsand statistics/Publications/PublicationsPolicyAndGuidance/DH_40 89101 [Accessed 12 June 2009].

3 National Institute for Health and Clinical Excellence (NICE) NHS Evidence Screening: Preconception Care. 2009. http://www.library.nhs.uk/SCREENING/ViewResource.aspx? res $I D=269308 \&$ tabID=289 [Accessed 12 June 2009].

4 Bukowski R, Malone FD, Porter FT, Nyberg DA, Comstock CH, Hankins GD, et al. Preconceptional folate supplementation and the risk of spontaneous preterm birth: a cohort study. PLoS Med 2009 6: e1000061. doi:10.1371/journal.pmed.1000061.

5 Gardiner H, Fouron J-C. Folic acid fortification and congenital heart disease. BMJ 2009; 338: b1144.

6 Food Standards Agency. Eat well, be well. Trying for a baby. 2009. http://www.eatwell.gov.uk/agesandstages/pregnancy/ trybaby [Accessed on 7 July 2009]

7 British Medical Association (BMA). Smoking and Reproductive Life: The Impact of Smoking on Sexual, Reproductive and Child Health. London, UK: British Medical Association, Science and Education Department, 2004. http://www.bma.org.uk/ ap.nsf/Content/smokingreproductivelife/\$file/smoking.pdf [Accessed 7 June 2009].

8 McDiarmid MA, Gehle K. Preconception brief: occupational/ environmental exposures. Matern Child Health J 2006; 10: S123-S128.

9 Inskip HM, Crozier SR, Godfrey KM, Borland SE, Cooper C, Robinson SM. Women's compliance with nutrition and lifestyle recommendations before pregnancy: general population cohort study. BMJ 2009; 338: b481.

10 Macintosh MCM, Acolet D, Bailey JA, Doyle P, Fleming KM, Golightly $\mathrm{S}$, et al. Perinatal mortality and congenital abnormalities in babies of women with type 1 or type 2 diabetes in England, Wales and Northern Ireland: population based study. BMJ 2006; 333: 177.

11 Royal College of Obstetricians and Gynaecologists (RCOG). RCOG Statement on Later Maternal Age. 2009. www.rcog.org.uk/what-we-do/ [Accessed 1 July 2009].

12 Ben-Shlomo $Y$, Kuh D. A life course approach to chronic disease epidemiology: conceptual models, empirical challenges and interdisciplinary perspectives. Int $J$ Epidemiol 2002; 31: 285-293. 